\title{
PENGARUH KEBERADAAN IKAN NILEM (Osteochilus hasselti) TERHADAP STRUKTUR KOMUNITAS ALGA PERIFITON
}

\section{INFLUENCE OF THE EXISTENCE OF NILEM FISH (Osteochilus hasselti) ON THE STRUCTURE OF COMMUNITY ALGAE PERIPHYTON}

\author{
Dandy Eka Putra Pagilalo ${ }^{1)^{*}}$, Sucahyo ${ }^{1)}$, Desti Cahyaningrum ${ }^{1)}$
}

\begin{abstract}
Diterima : 15 Juli 2020
Disetujui : 17 Agustus 2020
\end{abstract}

\section{Afiliasi Penulis: \\ 1) Fakultas Biologi, Universitas Kristen Satya Wacana, Surabaya, Indonesia}

\begin{tabular}{l}
\hline Alamat Korespondensi: \\
*dandypagilalo69@gmail.com \\
\hline
\end{tabular}

\section{Cara Sitasi:}

Pagilalo, DEP, Sucahyo, \& D. Cahyaningrum. 2020. Pengaruh keberadaan ikan nilem (Osteochilus hasselti) terhadap struktur komunitas alga perifiton: Journal of Tropical Biology 8 (3): 186-193.

\begin{tabular}{l} 
ABSTRAK \\
Perifiton merupakan salah satu komponen penting bagi ekosistem air yang \\
keberadaannya dipengaruhi banyak faktor, termasuk adanya predator. Ikan \\
Nilem (Osteocilus hasselti) merupakan salah satu predator alami alga perifiton. \\
Penelitian bertujuan untuk mengetahui pengaruh keberadaan Ikan Nilem (O. \\
hasselti) terhadap struktur komunitas perifiton yang ditumbuhkan pada substrat \\
buatan. Penelitian ini merupakan penelitian eksperimental terdiri atas empat \\
perlakuan dengan kepadatan O. hasselti sebagai variabel bebasnya. Perlakuan \\
tersebut meliputi perlakuan Pl (dua ikan), perlakuan P2 (empat ikan), \\
perlakuan P3 (delapan ikan), serta perlakuan tanpa ikan sebagai kontrol. \\
Starter perifiton berasal dari danau Rawa Pening, diambil menggunakan \\
plankton net, sedangkan ikan Nilem (O. hasselti) diperoleh dari penjual benih \\
ikan di Salatiga. Data yang diambil meliputi jumlah jenis, jumlah individu tiap \\
jenis, serta identifikasi jenis perifiton dalam sampel substrat. Data tersebut \\
kemudian digunakan untuk menganalisis struktur komunitas perifiton \\
berdasarkan indeks keanekaragaman spesies (H), indeks keseragaman (e), \\
kepadatan (J1), indeks dominansi (c), serta kekayaan spesies. Hasil perhitungan \\
setiap indeks kemudian dianalisis dengan uji two-way Anova untuk mengetahui \\
signifikansinya. Hasil analisis two way anova menunjukan bahwa jumlah ikan \\
berpengaruh terhadap indeks keanekaragaman alga perifiton dengan nilai rata- \\
rata H' perlakuan adalah 0,15 dibandingkan dengan H' kontrol yaitu 0,62. \\
Selain itu, jumlah hari berpengaruh terhadap indeks keseragaman dengan nilai \\
rata-rata e perlakuan O,18 dan nilai e kontrol adalah O,39. Sehingga \\
disimpulkan bahwa ikan Nilem (O.hasselti) berpengaruh terhadap struktur \\
komunitas alga perifiton pada substrat buatan, yaitu menyebabkan \\
keanekaragaman rendah. Sejalan dengan hal tersebut, pengamatan hari ke-7 \\
menunjukkan bahwa keberadaan ikan Nilem (O. hassellti) menyebabkan adanya \\
dominasi oleh Trachelomonas sp dan Strombomonas sp. \\
Kata kunci: Osteocilus hasselti, struktur komunitas, alga perifiton \\
\hline
\end{tabular}

\section{ABSTRACT}

Periphyton is one of the important components for aquatic ecosystem which existence is influenced by many factors, including predators. Nilem fish (Osteocilus hasselti) is one of the natural predators of periphyton algae. The study aims to explore the effect of the presence of Nilem fish (O. hasselti) on the structure of the Periphyton community grown on artificial substrates. The study is an experimental study consisting of four treatments with $O$. hasselti density as the independent variable. The treatment includes P1 (two fish) treatment, P2 (four fish) treatment, P3 treatment (eight fish), as well as no fish treatment as a control. Periphyton starter comes from Rawa Pening Lake, taken with plankton net, while Nilem fish (O. hasselti) are obtained from fish seed sellers in Salatiga. The Data taken includes the number of species, the number of individuals of each species, as well as identification of the type of periphyton in substrate 
sampl. The data is then used to analyse the structure of periphyton community based on the species diversity index $\left(H^{\prime}\right)$, uniformity index (e), density (J1), dominance index $(c)$, and species richness indeks. The result of the calculation each index are then analyzed with the two way Anova test to determine their significance. Results of the analysis of two way Anova showed that the number of fishes affecting the diversity index of periphyton with an average value of $h^{\prime}$ treatment is 0.15 compared with $h^{\prime}$ control 0.62. In addition, the number of days affects the index of uniformity with the average value of e treatment 0.18 and the value of e control is 0.39. Thus, it is concluded that Nilem fish (O. hasselti) affects the structure of the Periphyton algae community on artificial substrates, which is causing low diversity. In line with this, the 7th day observation shows that the existence of Nilem fish (O. hassellti) causes dominance by Trachelomonas sp and Strombomonas sp.

Keywords: Osteocilus hasselti, community structure, peripheral algae

\section{PENDAHULUAN}

Perifiton merupakan organisme perairan yang terdiiri dari bakteri, protozoa, dan alga. Perifiton berperan penting dalam suatu perairan yaitu sebagai produsen primer dan juga sebagai indikator pencemaran pada suatu ekosistem perairan [1]. Selain memengaruhi lingkungannya, alga perifiton secara timbal balik juga dipengaruhi oleh lingkungan tempat tinggalnya [2]. Faktor yang memengaruhi keberadaan alga perifiton antara lain faktor fisika, kimia, dan biologi. Hal ini dibuktikan oleh [3], yang menyatakan bahwa alga perifiton dari filum Chlorophyta dan diatom akan tumbuh dengan stabil pada kisaran suhu $20-30^{\circ} \mathrm{C}$, akan tetapi pada filum Cyanophyta memiliki toleransi pada kisaran suhu lebih dari $30^{\circ} \mathrm{C}$ [4] menyatakan bahwa suhu optimum untuk pertumbuhan mikroalga pada suatu ekosistem perairan adalah kisaran $24-28,5^{\circ} \mathrm{C}$. Faktor kimia juga memengaruhi keberadaan alga perifiton, dibuktikan oleh [5], yang menyatakan bahwa derajat keasaman merupakan faktor yang memengaruhi keberadaan kelas Chlorophyceae dan Cyanophyceae. Selain kedua faktor tersebut, faktor biologi juga berpengaruh terhadap keberadaan alga perifiton, misalnya keberadaan predator alami. Ikan Nilem (Osteochilus hasselti) adalah salah satu jenis ikan herbivor dan merupakan predator alami alga perifiton. Ikan Nilem ( $O$. hasselti) merupakan jenis ikan air tawar yang tergolong dalam anggota suku Cyprinidae. Pakan utama Ikan Nilem ( $O$. hasselti) di habitat aslinya yaitu kelompok alga perifiton seperti Bacillariophyceae dan Chlorophyceae [6]. Penelitian ini bertujuan untuk mengetahui pengaruh keberadaan Ikan Nilem $(O$. hasselti) terhadap struktur komunitas alga perifiton yang ditumbuhkan pada substrat buatan di laboratorium. Hasil penelitian akan menjadi sumber informasi baru mengenai pengaruh keberadaan ikan Nilem (O. hasselti) terhadap struktur komunitas alga perifiton. Informasi tersebut penting dan menjadi dasar bagi penelitian lanjutan, yaitu untuk mengetahui potensi pemanfaatan alga perifiton sebagai pakan alami ikan Nilem (O. hasselti).

\section{METODE PENELITIAN}

Penelitian ini merupakan penelitian eksperimental yang dilakukan di laboratorium. Pada penelitian ini, inokulan alga perifiton yang digunakan sebagai starter diperoleh dari air Danau Rawa Pening. Inokulan tersebut kemudian dikulturkan pada substrat buatan dalam wadah akuarium berukuran $40 \mathrm{~cm}$ x 30 $\mathrm{cm}$. Substrat buatan yang digunakan adalah object glass yang digantung pada dasar akuarium dengan posisi horizontal (Gambar 1). Substrat buatan (object glass) diletakkan di wadah akuarium pada hari ke-0. Sampel air yang digunakan sebagai media kultur dalam penelitian ini adalah campuran air PDAM yang telah diendapkan terlebih dahulu dan air Danau Rawa Pening dengan perbandingan (10\%: 90\%). Pemilihan air PDAM sebagai media kultur dilakukan dengan pertimbangan ketersedian dan kemudahan akses dibanding sumber air lainnya. Oleh karena itu, media kultur tersebut perlu diendapkan terlebih dahulu agar menghilangkan zat-zat kimia yang ada dalam air PDAM seperti kaporit. Pada wadah percobaan Ikan Nilem (Osteochilus hasselti) dimasukkan sebagai predator bagi kultur alga perifiton yang diamati. Ikan Nilem yang digunakan dalam penelitian ini berumur sekitar 1-2 bulan dengan ukuran tubuh ikan sekitar 4-5 cm. Benih ikan Nilem (O. hasselti) 
diperoleh dari penjual benih ikan di daerah Muncul, Salatiga, Jawa Tengah. Pada penelitian ini tidak dilakukan pemilihan jenis kelamin pada Osteochilus hasselti yang digunakan untuk perlakuan.

Pada penelitian ini, terdapat empat perlakuan dengan kepadatan ikan Nilem $(O$. hasselti) sebagai variabel bebasnya. Perlakuan tersebut meliputi perlakuan P1 (dua ekor), perlakuan P2 (empat ekor), dan perlakuan P3 (delapan ekor). Sebagai kontrol adalah perlakuan tanpa keberadaan predator ikan Nilem (O. hasselti) di dalam akuarium. Ulangan dilakukan sebanyak tiga kali pada setiap perlakuan. Selama penelitian Ikan Nilem (O.hasselti) diberi pakan tambahan (pelet berukuran $1 \mathrm{~mm}$ ) sebanyak dua kali sehari pada pukul 09.00 dan 15.00 WIB sejumlah $2 \%$ dari berat tubuhnya. Pada perlakuan kontrol tidak diberi penambahan pakan untuk mencegah penurunan kualitas media kultur. Sementara itu, penambahan pakan pada unit perlakuan diasumsikan tidak memengaruhi kualitas media kultur disebabkan pemberian pakan dilakukan secara seragam yaitu (2\% dari berat tubuh) dan dapat dipastikan pakan tersebut habis dimakan. Sehingga, diasumsikan bahwa kepadatan Osteochilus hasselti merupakan satu-satunya variabel bebas yang berpengaruh dalam penelitian ini. Penelitian ini juga lebih menitikberatkan pada pengaruh keberadaan Osteochilus hasselti, sehingga pengamatan parameter kualitas air tidak dilakukan. Selain itu, dilakukan penambahan aerasi pada unit percobaan sebagai suplai oksigen sehingga kualitas media kultur diasumsikan seragam dan telah memenuhi syarat tumbuh Osteochilus hasselti maupun alga perifiton. Suplai cahaya untuk pertumbuhan alga perifiton diperoleh secara alami dari matahari tanpa adanya tambahan pencahayaan.

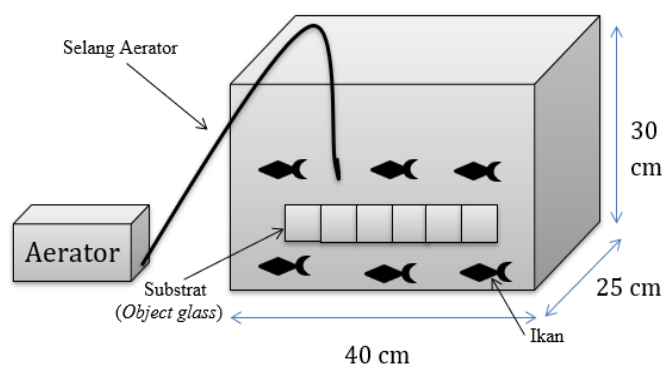

Gambar 1. Rancangan wadah akuarium penelitian (sumber: dok pribadi)
Pengambilan sampel dan pengambilan data berupa jumlah jenis, jumlah individu tiap jenis serta identifikasi jenis alga perifiton pada setiap unit percobaan dilakukan pada hari ke 7, 14, dan 21. Sampel yang diambil adalah sampel komunitas alga perifiton yang melekat pada substrat object glass. Pada setiap waktu sampling, diambil satu object glass dari tiap perlakuan. Penelitian ini menggunakan metode sampel terbuang, sehingga substrat object glass yang telah diamati tidak akan dikembalikan ke dalam akuarium. Dari sampel tersebut, diamati komunitas alga perifiton yang tumbuh pada substrat menggunakan bantuan mikroskop binokuler. Dalam pengamatan tersebut, digunakan lima titik bidang pandang yang telah ditentukan sebelumnya pada setiap substrat buatan (object glass). Lima titik bidang pandang tersebut yaitu sisi kiri, sisi kanan, sisi atas, sisi bawah, dan di tengah substrat buatan (object glass). Sebelum diamati, sampel komunitas alga perifiton terlebih dahulu diawetkan menggunakan larutan FAA. Pengamatan menggunakan mikroskop dilakukan tiga kali ulangan pengamatan. Setiap spesies alga perifiton yang teramati kemudian diidentifikasi nama serta jenisnya.

Data yang diperoleh kemudian digunakan untuk menganalisis struktur komunitas alga perifiton berdasarkan indeks keanekaragaman spesies, indeks keseragaman, indeks kepadatan, dan indeks dominansi, serta indeks kekayaan spesies (Tabel 1). Keseluruhan hasil akhir setelah perhitungan kemudian dianalisis secara statistik menggunakan two way Anova setelah dilakukan uji normalitas dan homogenitas.

Tabel 1. Rumus perhitungan berbagai parameter dalam analisis struktur komunitas

\begin{tabular}{cc}
\hline Indeks & Rumus \\
\hline $\mathrm{H}^{\prime}$ & $\mathrm{H}^{\prime}=-\sum \frac{n i}{N} \ln \frac{n i}{N}$ \\
$\mathrm{C}$ & $=\sum_{i=1}^{s}(p i)^{2}$ \\
$\mathrm{e}$ & $e=\frac{H^{\prime}}{\ln S}$
\end{tabular}




$$
\mathrm{Jl} \quad \mathrm{Jl}=\frac{P i}{5 x A x 3}
$$

\section{HASIL DAN PEMBAHASAN}

Hasil penelitian menunjukkan bahwa dari semua unit percobaan pada hari ke-0 tidak ditemukan adanya tanda-tanda keberadaan alga perifiton sehingga data hari ke-0 tidak dianalisis lebih lanjut. Sedangkan pada hari ke7 ditemukan 18 jenis spesies alga perifiton yang terdiri dari lima kelas yaitu Bacillariophyceae (tujuh jenis), Cyanophyceae (empat jenis), Chlorophyceae (dua jenis), Cryptophyceae (tiga jenis), dan Euglenophyceae (dua jenis). Dari lima kelas tersebut, pada perlakuan P1, P2, dan P3 hanya ditemukan tiga kelas yaitu Bacillariophyceae (tiga jenis), Chlorophyceae (satu jenis), Euglenophyceae (dua jenis). Sedangakan pada perlakuan kontrol ditemukan semua jenis dari lima kelas tersebut.

Bacillariophyceae merupakan salah satu jenis alga perifiton yang berperan penting sebagai produsen primer serta memiliki alat perekat yang memungkinkannya menempel pada substrat dengan lebih mudah dibanding kelas lainnya [7]. Kelas Cyanophyceae merupakan jenis alga biru-hijau atau ganggang yang memiliki sel tunggal, bentuk seperti benang dengan struktur tubuh yang sederhana dan bersifat autotrof [8]. Kelas Chlorophyceae (alga hijau) merupakan kelompok perifiton yang sebagian besar hidup di air tawar. Chlorophyceae ini juga merupakan produsen primer perairan dalam menghasilkan oksigen dalam air karena anggota-angota dari kelas ini memiliki banyak kandungan klorofil sehingga dapat berfotosintesis dengan maksimal [9]. Kelas Cryptophyceae merupakan kelompok uniseluler yang tidak memiliki kedekatan dengan kelompok alga lain. Kelompok ini biasanya memiliki memiliki warna kecoklatan. Kelas Euglenophyceae masuk dalam kelompok fitoplankton bersel satu dan dapat berfotosintesis karena memiliki kloroplas berwarna hijau. Kelompok Euglenophyceae ini hidup sebagai organisme fotoautotrof melalui proses fotosintesis. Akan tetapi dalam kondisi kekurangan cahaya matahari, kelompok ini tetap dapat hidup sebagai organisme heterotroph dengan memanfaatkan bahanbahan organik dalam air [10]. Jumlah spesies terbanyak yang ditemukan dalam penelitian adalah pada Kelas Bacillariophyceae yaitu sebanyak tujuh jenis spesies alga perifiton. Menurut [11], Kelas Bacillariophyceae memiliki perananan penting pada produksi primer perairan sehingga lebih mendominasi dibandingkan dengan alga perifiton kelas yang lain, dan juga merupakan sumber makanan utama bagi zooplankton.

Data mengenai jumlah spesies pada setiap perlakuan, kemudian digunakan untuk menghitung indeks kekayaan spesies. Hasilnya menunjukkan bahwa indeks kekayaan spesies alga perifiton tertinggi terdapat pada perlakuan kontrol pada hari ke-7 yaitu 6,33. Pada perlakuan $\mathrm{P} 1, \mathrm{P} 2$, dan $\mathrm{P} 3$, indeks kekayaan jenisnya pada hari ke-7 lebih rendah dibandingkan kontrol. Hal ini juga berlaku pada pengamatan hari ke-14 dan 21 (Gambar 2). Hasil tersebut menunjukkan bahwa keberadaan ikan Nilem (O. hasselti) berpengaruh terhadap indeks kekayaan spesies alga perifiton. Diduga, hal tersebut terjadi karena beberapa jenis alga perifiton di perlakuan P1, P2, dan P3 merupakan pakan alami ikan Nilem $(O$. hasselti) sehingga terjadi predasi yang menyebabkan berkurangnya kekayaan spesies.

Berdasarkan hasil penelitian ini, diketahui bahwa terdapat beberapa jenis alga perifiton yang berpotensi sebagai makanan alami oleh ikan Nilem (O. hasselti) yaitu berasal dari Kelas Bacillariophyceae, Cyanophyceae, Chlorophyceae, serta Cryptophyceae. Hal tersebut karena pada pengamatan hari ke-7, keempat kelas alga perifiton tersebut hanya ditemukan pada perlakuan kontrol dan tidak ditemukan pada perlakuan P1 hingga P3. Sehingga dapat disimpulkan bahwa dari kelima kelas alga perifiton yang palatable (dapat dimakan oleh ikan) adalah jenis alga perifiton dari Kelas Bacillariophyceae, Cyanophyceae, Chlorophyceae, serta Cryptophyceae. Hal tersebut didukung oleh [6], yang menyatakan bahwa terdapat tiga kelas alga yang ditemukan di usus ikan Nilem (O. hasselti) di karamba jaring apung di waduk Ir. H. Djuanda, yaitu Bacilliariophyceae, Cyanophyceae, dan Chlorophyceae. 


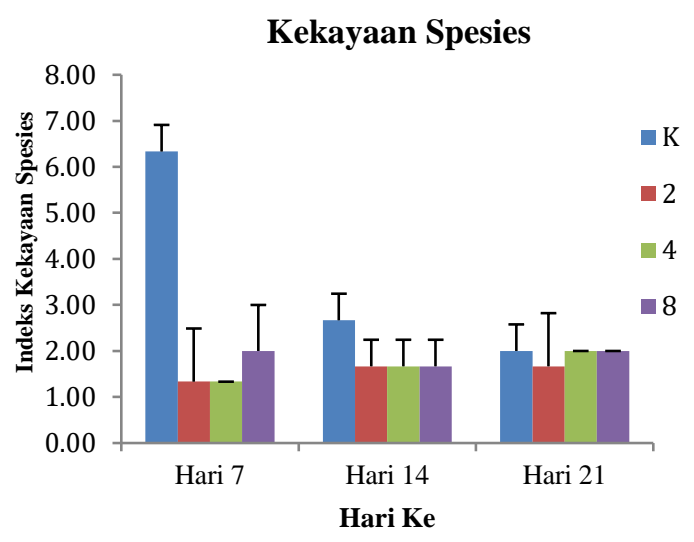

Gambar 2. Pengaruh keberadaan ikan Nilem (Osteochilus hasselti) terhadap indeks kekayaan spesies alga perifiton pada hari ke-7, 14, dan 21

Menurut [12], indeks kekayaan jenis akan berbanding lurus dengan indeks keanekaragaman. Artinya, semakin tinggi indeks kekayaan jenis, maka indeks keanekaragamannya juga akan semakin naik dan berlaku sebaliknya. Hasil penelitan ini sejalan dengan pernyataan tersebut. Dalam penelitian, diketahui bahwa indeks keanekaragaman tertinggi ada di perlakuan kontrol pada hari ke-7 yang juga memiliki indeks kekayaan jenis tertinggi. Indeks keanekaragaman pada perlakuan kontrol hari ke-7 adalah 1,00 - 1,18. Berdasarkan kriteria [13], nilai rata-rata indeks keanekaragaman tersebut tergolong dalam kategori sedang. Sementara itu, indeks keanekaragaman pada perlakuan lain tergolong dalam kategori rendah, yaitu sebesar 0,02 - 0,26 untuk perlakuan P1, sebesar 0,01 - 0,31 untuk perlakuan $\mathrm{P} 2$, dan 0,13-0,31 untuk perlakuan P3 (Gambar 3).

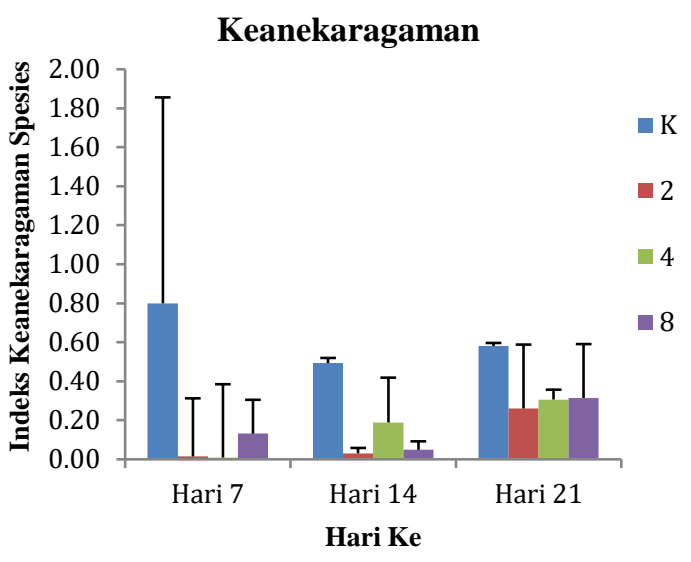

Gambar 3. Pengaruh keberadaan ikan Nilem (Osteochilus hasselti) terhadap indeks keanekaragaman spesies alga perifiton pada hari ke-7, 14, dan 21

Gambar 3 juga menunjukkan penurunan nilai indeks keanekaragaman setiap minggunya pada perlakuan P1, P2, dan P3. Hal tersebut terjadi karena adanya cekaman ikan Nilem $(O$. hasselti) sebagai predator bagi alga perifiton yang menyebabkan berkurangnya keanekaragaman jenis alga perifiton akibat dominansi jenis alga tertentu yang bukan menjadi pakan predator tersebut. Pada kontrol, juga terjadi penurunan indeks keanekaragaman yang diduga terjadi karena dominansi jenis alga tertentu. Berbeda dengan dominasi pada perlakuan dengan predator, pada kontrol dominansi lebih disebabkan karena perbedaan adaptasi di antara alga perifiton terhadap perubahan lingkungan dalam akuarium. Dugaan adanya dominansi yang menyebabkan penurunan indeks kekayaan dan keanekaragaman spesies dalam penelitian ini diperkuat dengan hasil perhitungan indeks dominansi pada setiap perlakuan (Gambar 4). Indeks dominansi cenderung lebih tinggi pada perlakuan yang menunjukkan indeks keanekaragaman yang relatif rendah. Misalnya, pada kontrol hari ketujuh yang memiliki indeks keanekaragaman paling tinggi, yaitu 1,18, memiliki indeks dominansi yang paling rendah, yaitu 0,55. Sebaliknya, P3 hari ke-7 memiliki indeks keanekaragaman yang rendah yaitu 0,01 , memiliki indeks dominansi tertinggi, yaitu 0,99 . Hal tersebut sejalan dengan pernyataan [14] yang menyatakan bahwa semakin kecil indeks keanekaragaman suatu spesies menandakan bahhwa ada dominansi dari spesies lain, sehingga nilai indeks keanekaragamannya turun atau rendah, begitu juga sebaliknya.

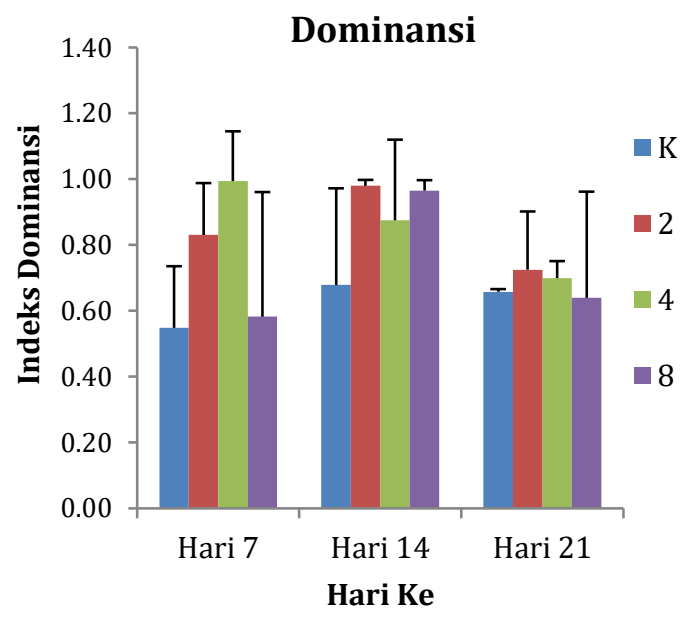


Gambar 4. Pengaruh keberadaan ikan Nilem (Osteochilus hasselti) terhadap indeks dominansi spesies alga perifiton pada hari ke 7,14 , dan 21

Selain itu, secara keseluruhan indeks dominansi pada perlakuan berkisar antara 0,55-0,99. Menurut [13] jika indeks dominansi lebih dari 0,5 menunjukkan adanya dominansi dari satu spesies atau beberapa spesies. Pada penelitian ini, terdapat lima kelas alga perifiton yang di temukan di awal penelitian (hari ke-7). Namun tidak semua spesies alga perifiton tersebut disukai atau dimanfaatkan ikan Nilem (Osteochilus hasselti) sebagai makanan, sehingga ada spesies tertentu yang tetap hidup hingga mendominasi sampai hari ke-21. Hal ini sesuai dengan penelitian [15] yang menunjukkan bahwa dari tiga kelas fitoplankton yang ditemukan (Bacillariophyta, Chlorophyta, dan Cyanophyta), hanya jenis Cyanophyta dan Chlorophyta saja yang dimanfaatkan Oreochormis niloticus sebagai makanannya. Hal ini menunjukkan bahwa ikan memiliki kebiasaan memilih makanan yang disukainya saja. Sementara itu, jenis alga perifiton yang mendominasi pada penelitian ini merupakan spesies alga perifiton yang ada dalam Kelas Euglenophyceae, yaitu Trachelomonas sp. dan Strombomonas sp. Kedua spesies alga perifiton tersebut ditemukan hampir di semua perlakuan dari hari ke-7 sampai hari ke-21. Dengan kata lain spesies Trachelomonas sp. dan Strombomonas sp. diduga tidak disukai oleh ikan Nilem $(O$. hasselti) sehingga terus bertambah banyak dan menyebabkan nilai indeks dominansi dari hari ke-7 hingga hari ke-21 relatif tinggi.

Selain itu, adanya dominansi Trachelomonas $s p$ dan Strombomonas $s p$ diduga juga memengaruhi indeks keseragaman komunitas alga perifiton yang sedang diamati. Menurut [14], jika nilai indeks keanekaragaman semakin kecil, maka nilai indeks keseragaman juga akan semakin kecil begitu pula sebaliknya, serta menandakan adanya dominansi dari spesies lain. Perhitungan indeks keseragaman dilakukan untuk mengetahui keseimbangan komunitas pada kesamaan jumlah individu dari tiap-tiap spesies. [14] mengatakan jika jumlah individu tiap spesies semakin mirip dan penyebarannya semakin merata, maka derajat keseimbangan dari tiap-tiap spesies juga akan semakin besar. Hal ini menunjukkan bahwa nilai indeks keanekaragaman berpengaruh terhadap nilai keseragaman spesies. Pada penelitian, nilai indeks keseragaman spesies pada hari ke-21 lebih tinggi yaitu 0,26-0,58 dibandingkan dengan hari ke-7 dan 14. Selain itu, indeks keseragaman pada perlakuan kontrol lebih tinggi dari pada $\mathrm{P} 1, \mathrm{P} 2$, dan $\mathrm{P} 3$ yaitu $0,22-0,48$ (Gambar 5). Hal tersebut dikarenakan tidak adanya predator, yaitu ikan Nilem (O. hasselti) pada perlakuan kontrol.

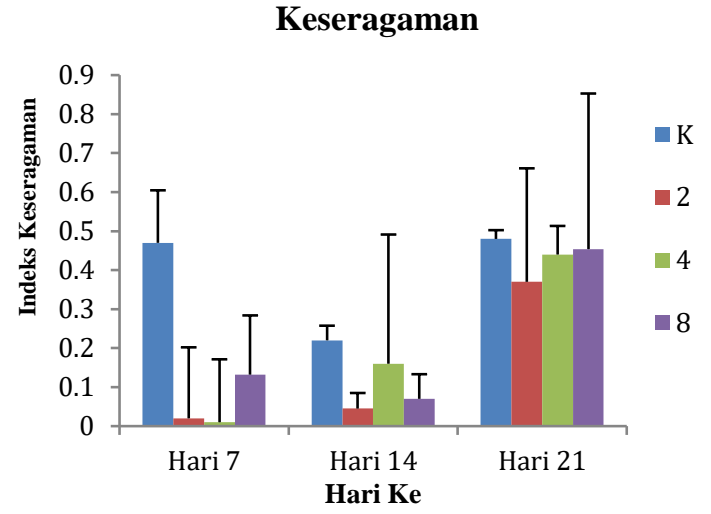

Gambar 5. Pengaruh keberadaan ikan Nilem (Osteochilus hasselti) terhadap indeks keseragaman spesies alga perifiton pada hari ke-7, 14, dan 21

Dominansi oleh Trachelomonas sp. dan Strombomonas sp. diduga juga terjadi karena adanya kemampuan adaptasi yang lebih tinggi dibanding spesies lainnya. Berdasarkan data indeks kepadatan (Gambar 6) diketahui bahwa kepadatan semakin meningkat seiring dengan lamanya waktu pengamatan. Peningkatan kepadatan tersebut diduga menyebabkan kondisi lingkungan di akuarium yang menjadi wadah kultur juga mengalami perubahan. Akibatnya, tidak semua spesies mampu bertahan menghadapi perubahan tersebut sehingga mati. Sebaliknya, pada spesies dari Kelas Euglenophyceae yaitu Trachelomonas sp. dan Strombomonas sp. diduga mampu beradaptasi dengan baik sehingga tetap bertahan. Dugaan tersebut diperkuat dengan pernyataan [7] dalam [16] yang menyatakan bahwa di perairan tercemar kelompok Cyanophyta dan Euglenophyta dapat mendominasi baik jenis ataupun densitasnya karena kedua kelompok tersebut digunakan sebagai indikator adanya pencemaran oleh bahan organik dalam suatu perairan. Dugaan tersebut diperkuat dengan pernyataan [10] yang menunjukkan bahwa Trachelomonas sp. 
dapat hidup dengan baik pada keadaan yang tidak mendukung sekalipun seperti kekurangan cahaya matahari dan lingkungan perairan yang kaya akan bahan-bahan organik serta memiliki tingkat pembusukan yang tinggi.

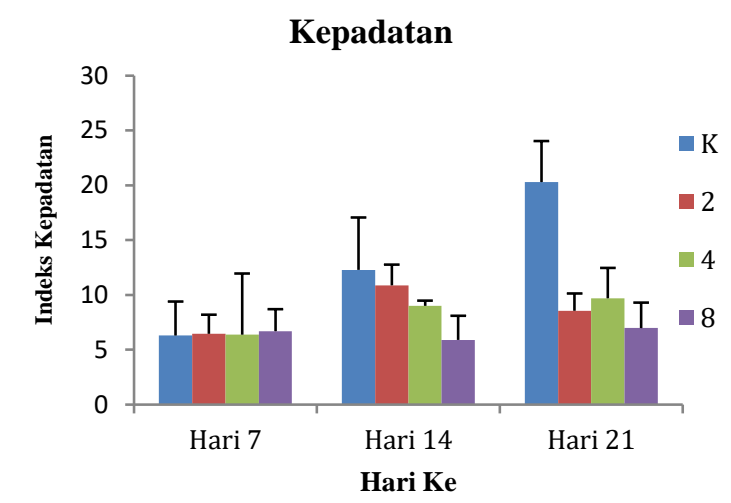

Gambar 6. Pengaruh keberadaan ikan Nilem (Osteochilus hasselti) terhadap indeks kepadatan spesies alga perifiton pada hari ke-7, 14, dan 21

Hasil perhitungan setiap indeks kemudian dianalisis dengan uji two way anova untuk mengetahui signifikansinya (Tabel 2). Hasil analisis two way Anova menunjukan bahwa jumlah ikan berpengaruh terhadap indeks keanekaragaman alga perifiton dengan signifikansi sebesar 0,04. Selain itu, jumlah hari berpengaruh terhadap indeks keseragaman dengan signifikansi sebesar 0,01.

Tabel 2. Hasil analisis SPSS two way Anova

\begin{tabular}{ccccc}
\hline No & Dependent & Independent & Sig. & Kesimpulan \\
\hline 1 & M & Ikan & 0,23 & Tidak Signifikan \\
& & Hari & 0,58 & Tidak Signifikan \\
2 & \multirow{2}{*}{ H' } & Ikan & 0,04 & Signifikan \\
& & Hari & 0,56 & Tidak signifikan \\
3 & \multirow{2}{*}{ c } & Ikan & 0,20 & Signifikan \\
& & Hari & 0,16 & Tidak Signifikan \\
4 & \multirow{2}{*}{ e } & Ikan & 0,10 & Tidak Signifikan \\
& & Hari & 0,01 & Signifikan \\
5 & \multirow{2}{*}{ J1 } & Ikan & 0,21 & Tidak Signifikan \\
& & Hari & 0,18 & Tidak Signifikan \\
\hline
\end{tabular}

\section{KESIMPULAN}

Ikan Nilem (Osteochilus hasselti) berpengaruh terhadap struktur komunitas alga perifiton pada substrat buatan, yaitu sebagai predator bagi alga kelas Bacillariophyceae, Cyanophyceae, Chlorophyceae, serta Cryptophyceae. Predasi tersebut menyebabkan keanekaragaman rendah, kepadatan rendah, penyebaran individu yang tidak merata pada struktur komunitas alga perifiton, serta adanya dominasi oleh Trachelomonas sp. dan Strombomonas sp.

\section{DAFTAR PUSTAKA}

[1] Abwao JO, Boera PN, Munguti JM, Orina PS, Ogello EO (2014) The potential of periphyton based aquaculture for Nile tilapia (Oreochromis niloticus L.) production a review. International Journal of Fisheries and Aquatic Studies 2 (1): 147-152.

[2] Sawestri S, Dwi A (2015) Status kualitas Sungai Musi bagian hilir ditinjau dari komunitas perifiton. Seminar Nasional Perikanan Indonesia. 19-20 November 2015. STP Jakarta.

[3] Juanda M, Hijriah, Hala Y (2013) Identifikasi perifiton sebagai penentu kualitas air pada tambak ikan Nila (Oreochromis niloticus). Jurnal Bionature 14(1): 16-24.

[4] Awal J, Tantu H, Tenriawaru EP (2014) Identifikasi alga (Algae) sebagai bioindikator tingkat pencemaran di Sungai Laasi Kabupaten Luwu. Jurnal Dinamika 05 (2): 21-34.

[5] Andriansyah, Setyawati TR, Lovadi I (2014) Kualitas perairan kanal Jawi dan Sungai Raya Dalam Kota Pontianak ditinjau dari struktur komunitas mikroalga perifitik. Jurnal Protobiont 3 (1): 61-70.

[6] Ekawati D, Astuty S, Dhahiyat Y (2011) studi kebiasaan makan ikan Nilem (Osteochilus hasselti) yang dipelihara pada karamba jaring apung di Waduk Ir. H. Djuanda, Jawa Barat. Jurnal Akuatika 2 (1): 1-12.

[7] Sachlan M (1982) Planktonologi. Semarang, Fakultas Peternakan dan Perikanan UNDIP.

[8] Tjitrosoepomo (1994) Jenis Algae dalam pengenalan jenis-jenis rumput laut Indonesia. Jakarta: Puslitbang Oseanologi LIPI.

[9] Sulisetijono (2009) Bahan Serahan Alga. Malang: UIN Malang.

[10] Sulastri (2018) Fitoplankton danau-danau di Pulau Jawa. Jakarta, LIPI Press.

[11] Suwartimah K, Widianingsih W, Hartati R, Wulandari SY (2012) Komposisi jenis dan kelimpahan diatom bentik di Muara 
Sungai Comal Baru Pemalang. Indonesian Journal of Marine Sciences 16 (1): 16-23.

[12] Nahlunnisa H, Ervizal AMZ, Dan YS (2016) Keanekaragaman spesies tumbuhan di areal Nilai Konservasi Tinggi (NKT) Perkebunan Kelapa Sawit Provinsi Riau. Media Konservasi 21(1): 91-98.

[13] Odum EP (1996) Dasar-dasar Ekologi. Edisi Ketiga.Yogyakarta, Gadjah Mada University Press.

[14] Insafitri (2010) Keanekaragaman, keseragaman, dan dominansi bivalvia di area buangan lumpur Lapindo muara Sungai Porong. Jurnal Kelautan 3 (1): 54 -59 .

[15] Setiawati SD, Rosa DP (2017) Studi makanan dan pertumbuhan ikan Nila (Oreochormis niloticus) di Rawa Biru Distrik Sota Kabupaten Merauke. Jurnal Fisherina 1 (1).

[16] Satino, Sudarsono WS (2012) Struktur komunitas fitoplankton sebagai bioindikator kualitas perairan "Telaga" Di Kabupaten Gunungkidul Yogyakarta. Prosiding Seminar Nasional dalam rangka Dies Natalis ke-48 Universitas Negeri Yogyakarta. 11-12 Mei 2012. LPPM UNY. 